\title{
LA TUMBA DE HIERRO DEL EMPRESARIO Francisco Peña Vaquero
}

\author{
THE IRON TOMB OF THE ENTREPRENEUR \\ Francisco Peña Vaquero
}

Ma Dolores Palazón Botella *

José Antonio Molina Gómez **

Recibido: 06/07/2020 - Aceptado: 24/04/2021

Doi: https://dx.doi.org/10.6018/rmu.435721

Publicado bajo licencia CC BY-SA

\section{Resumen}

El cementerio Nuestro Padre Jesús de Murcia atesora una tumba de hierro única, impulsada por Francisco Peña Vaquero, un industrial propietario de una de las fundiciones más importantes de la Murcia en el cruce de los siglos XIX y XX, para el que el trabajo lo era todo. Sobre ese material se proyectaría un programa iconográfico que combina elementos tradicionales del mundo de la muerte con un repertorio centrado en los propios útiles de su actividad profesional. La suma de todo ello daría como resultado un catafalco desde el que se proclamaban los ideales de la resurrección cristiana a partir del esfuerzo laboral desarrollado durante la vida. Analizar estos aspectos y vincularlos con los aportes económicos y funerarios de su contexto nos dará las pautas para abordar el análisis de su significado.

\section{Palabras clave}

Francisco Peña, fundición, hierro, iconografía, tumba, Murcia.

\begin{abstract}
The cemetery of Nuestro Padre Jesús in Murcia treasures a unique iron tomb, promoted by Francisco Peña Vaquero, an industrialist and owner of one of the most important foundries in Murcia at the crossroads of the nineteenth and twentieth centuries, for whom work was everything. An iconographic program was projected on iron combining traditional elements of the world of death with a repertoire centered on the tools of his professional activity. The sum of all this would result in a catafalque from which the ideals of Christian resurrection were proclaimed from the labor effort developed during life. Analyzing these aspects and linking them with the economic and funerary contributions of their context will give us the guidelines to approach the analysis of their meaning.
\end{abstract}

\section{Key words}

Francisco Peña, iron foundry, iron, iconography, grave, Murcia.

\footnotetext{
* Área de Historia del Arte de la Universidad de Murcia. Email: mdolorespb@um.es.

** Área de Historia Antigua de la Universidad de Murcia. Email: jamolgom@um.es.
} 


\section{UNA VIDA DEDICADA AL TRABAJO: LA PROYECCIÓN INDUSTRIAL DE FRANCISCO PEÑA EN LA MURCIA DEL SIGLO XIX *}

El 15 de septiembre de 1907, a la edad de 73 años, fallecía en la ciudad de Murcia el empresario Francisco Peña Vaquero. Tras ser velado y despedido en un funeral que debía inaugurar su vida en el mundo de los bienaventurados, fue conducido al Cementerio de Nuestro Padre Jesús. Desde allí la comitiva se dirigió hacia la calle San Fulgencio, donde le aguardaba su morada eterna. Un panteón único, hecho en hierro, realizado bajo su observancia por diversas manos, que fue ejecutado en su propia empresa, como quedó resaltado en su acceso: "Construido en los talleres de D. Francisco Peña. Murcia 1899». Esta referencia, más que una reflexión sobre el hecho de la muerte y la fugacidad de la vida, como era normal en estos repertorios, resultaba ser un eslogan publicitario, destinado a perpetuar no solo la impronta de tan insigne personaje sino la de su legado industrial. Estos aspectos se fusionaron en un ejercicio que logró aunar proyección personal, muerte e industria a partes iguales; cuestiones que no distorsionaban, si para él la vida era trabajo y la muerte para el cristiano era la verdadera vida, en ella la referencia industrial tenía tanto sentido como los elementos sacados de un tradicional muestrario iconográfico funerario. No en vano, su promotor era el fiel ejemplo de un hombre hecho a sí mismo, que gracias a su tesón y esfuerzo logró convertirse en un insigne industrial, cuya fama trascendió las fronteras de un país que apenas tenía repercusión en el exterior.

\subsection{De aprendiz a industrial: La formación de un empresario de éxito}

Francisco Peña había nacido en Sagunto el 29 de marzo de 1834. Al parecer en su familia la carpintería era el oficio a seguir, pero, tras pasar por él, vio que no se ajustaba a sus pretensiones y con 14 años comenzó a trabajar como aprendiz en un taller de cerrajero. Conviene tener en cuenta que el oficio de cerrajero durante siglos había sido uno de los más duros y complicados, al ser el encargado de realizar trabajos en hierro forjado de forma manual. El desarrollo de la técnica del hierro fundido durante la industriali-

\footnotetext{
* El presente texto es fruto de la conferencia «Un europeo en Murcia: El empresario Francisco Peña Vaquero", presentada en el marco del $2^{\circ}$ Simposio de Culturas Funerarias en Europa, celebrado en Murcia en marzo de 2020. En él, desarrollamos el trabajo: Griñán Montealegre, M., López Sánchez, M. \& Palazón Botella, M. D. (2008). Francisco Peña Vaquero y la fundición de hierro en Murcia. En Álvarez Areces, M. Á. (coord.), Del hierro al acero. Forjando la historia del patrimonio industrial metalúrgico. Gijón: CICEES, 261-273.
} 
zación y la consolidación de una maquinaria, que ayudaba a ejecutar parte de las tareas, permitió que la manualidad del oficio se fuera sustituyendo (Giedion, 1978: 68-69). Estos cambios comenzaron a gestarse en el siglo XIX, coincidiendo con su formación laboral, a la que sumó el «cultivo de las letras, en cuyo campo hacia proezas el joven Peña, a la par que con el yunque y con la lima». ${ }^{1}$ Aficionado al dibujo, se dice que ello le ayudó a desarrollar el arte de la modelación que tanto tendría que ver con su futuro oficio. ${ }^{2}$ De Sagunto se trasladó a Valencia, uno de los polos industriales más representativos en lo que se refiere a la fundición del hierro, con el ejemplo de la «Fundición Primitiva Valenciana» (Mañas, 2013), donde lograría establecerse por su cuenta en 1855 como cerrajero, construyéndose el mismo su banco de trabajo. Regresó un año después a Sagunto para contraer matrimonio con Ascensión Manquez Galiana, madre de sus dos hijos: Elvira y Magín Peña. A partir de entonces su biografía se entroncó con la José Campo Pérez, marqués de Campo, quien desde Valencia impulsó varias actividades empresariales, entre ellas diversas líneas ferroviarias. Peña estuvo como encargado en las obras del ferrocarril que unió Valencia con Tarragona, y posteriormente fue maestro en los talleres de herrería y reparación del túnel de Oropesa. En 1864 pasó a trabajar a la compañía de Ferrocarriles del Noroeste.

Instalado en Murcia, abrió dos ferreterías, una en la calle Trapería n. 70 y otra en el plano de San Francisco n. ${ }^{\circ} 5$. Pero ello no le hizo olvidar su oficio y entre 1864-1868 fundó un taller de camas y cerrajería que acabaría transformándose en una fundición. ${ }^{3}$ De este modo lograba proveerse de los mismos productos que vendía en sus comercios, consiguiendo ajustar precios y lograr calar entre la clientela local. Su actividad empresarial no se ceñiría solo a estos negocios, pues participó en subastas de obras públicas y construyó carreteras regionales, labor que sería continuada por su hijo. Y como accionista tuvo participaciones en la fábrica de cervezas y bebidas gaseosas «La Confianza», ${ }^{4}$ así como en varias explotaciones mineras de Cartagena y Jumilla. ${ }^{5}$

Esta ingente actividad industrial y empresarial con negocios diversos, ponía de relieve que Peña no se ajustaba al perfil industrial que tradicional-

\footnotetext{
${ }^{1}$ Archivo Municipal de Murcia (AMM). Hemeroteca. El Diario de Murcia. 11/10/1894. p. 1.

2 Ibídem.

3 Hemeroteca Digital Biblioteca Nacional de España. El Liberal de Madrid, 20/04/1899, pp. 1-2.

${ }^{4}$ Archivo General de la Región de Murcia (AGRM). Protocolo 11155: 267r-270v.

5 AGRM. Protocolo 12962: 225r-234v.
} 
mente refrendaba el sudeste peninsular, donde la industrialización se considera un capítulo en blanco y la sagacidad industrial algo inexistente. Aunque lo cierto es que, en este contexto extendido, que enmarca una predisposición desalentadora para abordar el hecho industrial, no se ajustaba a la realidad. Basta con remarcar los datos de la estadística industrial de 1886, donde se refrendaba que en la provincia de Murcia había 1.196 minas, de donde se extraían diversos minerales, habiéndose obtenido en el caso del hierro 422.539 toneladas. $^{6} \mathrm{El}$ auge de la minería impulsó los negocios auxiliares que esta necesitaba y las fundiciones de minerales coparon el área de Cartagena. Frente a ello, la ciudad de Murcia trataba de sumarse a la industrialización recomponiendo su actividad agroalimentaria con nuevas industrias harineras, la consolidación del sector pimentonero y el inicio de la industria conservera vegetal. A la par que los nuevos ingenios para el trabajo en el campo y la huerta, hechos en materiales resistentes y en donde la mecanización trataba de abrirse paso, permitían sustituir los utensilios de antaño y darles nuevos referentes que modernizarían la forma de abordar un mismo trabajo (Griñán, López, Palazón, 2008: 261-273).

Fue en este contexto donde Peña abrió su «Fábrica de Camas y Fundición de Hierro y demás Metales. Talleres de Construcción y Maquinaria». Una instalación ubicada en lo que acabaría siendo el barrio del Carmen de la capital, en el Paseo de Corvera, alejada del centro histórico de la ciudad, donde se asentaron diversas instalaciones que hicieron de esta zona un foco industrial, que contaría con el apoyo de la estación de ferrocarril, y estaba en las inmediaciones de la vía que comunicaba Cartagena con Murcia. ${ }^{7}$

\section{2. «La Fábrica de Camas y Fundición de Hierro y demás Metales. Talleres de Construcción y Maquinaria»: Un modelo de fábrica europea en Murcia}

El edificio fue varias veces descrito y analizado en la prensa local en glosas que, a falta de la documentación original sobre este centro de trabajo, nos ofrecen datos para recomponer sus dimensiones y configuración:

\footnotetext{
6 AMM. Hemeroteca. El Diario de Murcia. 28/08/1886. p. 2.

7 En el Barrio del Carmen también se ubicó «El Vulcano» (AMM. Hemeroteca. El Diario de Murcia. 29/09/1885. p. 4), la «Fundición de Hierro y Talleres» de la calle Cartagena (AMM. Hemeroteca. El Diario de Murcia. 04/06/1895. p. 3), y «La Primitiva Murciana» (AMM. Hemeroteca. El Diario de Murcia. 06/07/1886. p. 4).
} 


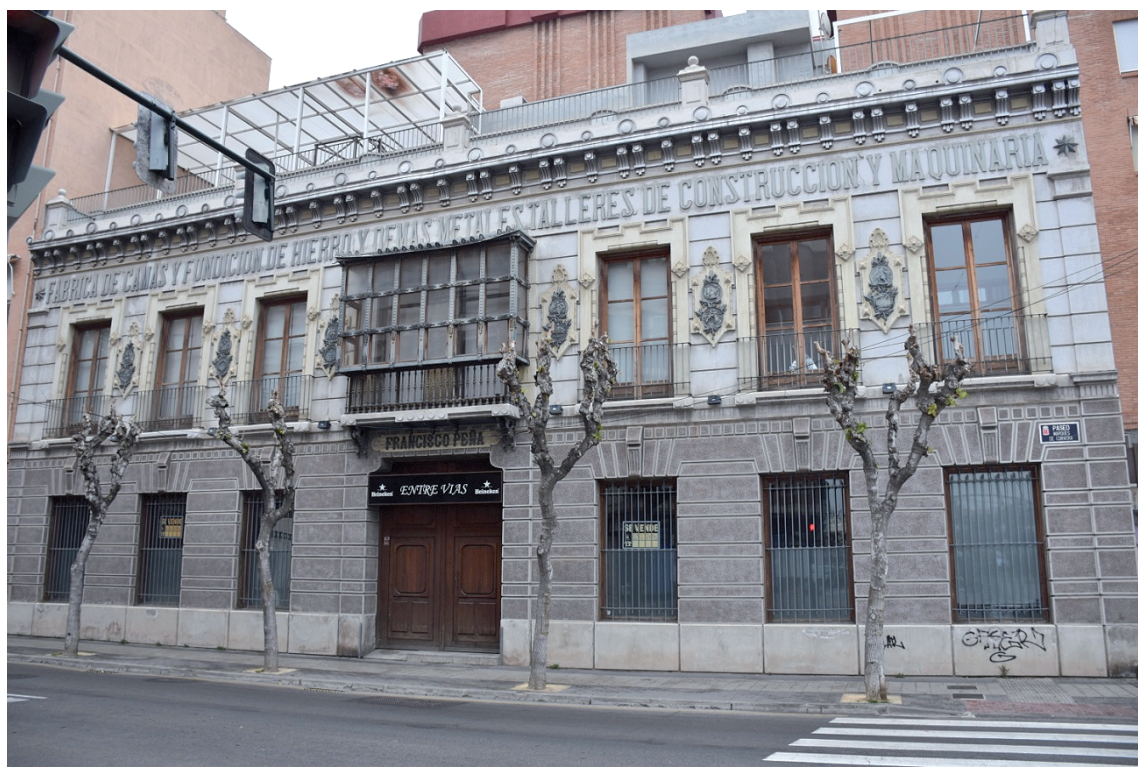

Imagen 1. Edificio conservado de la Fundición Peña en la ciudad de Murcia, Paseo marqués de Corvera. Autora: Palazón.

"Constitúyela un vastísimo edificio de 8.153 metros cuadrados, con muchas y amplias dependencias, enclavado en el Paseo del Marqués de Corvera, junto a la Estación férrea del Mediodía.

Examinada la tal fábrica con detención, nada se echa allí de menos. Sus elevados techos; sus grandiosos talleres, desde el de dibujo, al de modelación, fundición, construcción, montaje y pintura, todo está allí representado grandiosa y magistralmente, bajo la activa y sabia dirección de nuestro biografiado.

Hermosos jardines alegran la vista de los obreros allí ocupados, que son algunos centenares, siendo a la vez admirados de cuantos forasteros les visitan.

Todo lo que representa higiene y adelanto en la industria de que se trata lo tiene en su grandiosa fábrica perfectamente aplicado, el Sr. Peña Vaquero.

La luz eléctrica, es la que campea por el vastísimo edificio; con infinidad de lámparas voltáicas de 500 bujías cada una.

La ciencia médico-farmacéutica, tiene también allí su sitial, y es de admirar el magnífico y bien provisto botiquín.

En una palabra; es absolutamente imposible encontrar allí la mas pequeña falta, por escudriñador é inteligente que sea quien la examine.

¡No en valde ha sido la admiracion, hasta de inteligentes extranjeros que la han visitado!».8

8 AMM. Hemeroteca. El Diario de Murcia. 11/10/1894. p. 1. La referencia ha sido copia siguiendo la disposición literal del texto. 
Esta descripción, sin perder de vista que era un ejercicio propagandístico en el que los aspectos negativos no tendrían cabida, remarcaba la grandiosidad espacial de un complejo diseñado para albergar las diversas secciones que participarían del trabajo. Junto a ello, destacaba la inclusión de zonas ajardinadas, espacios que no solo estarían destinados, como se dice, a alegrar la vista a los obreros, sino a crear un ambiente de trabajo que permitiera a estos disponer de los beneficios de una zona de este tipo. Conviene remarcar lo novedoso de este principio.

Tengamos en cuenta que el higienismo había impulsado la creación de zonas de recreo y descanso ajardinadas en las ciudades, así como defendía que los espacios de trabajo recrearan un ambiente adecuado, donde debía primar la ventilación y la luz. En Inglaterra, Robert Owen (1771-1858), industrial e impulsor del movimiento obrero a la vez, había promovido un nuevo concepto de centro de trabajo, desarrollado en New Lanark, donde la fábrica se trasladaba a una colonia dotada de todos los servicios que sus obreros pudieran necesitar. Estas ideas se sumaron a las plasmadas por Ebenezer Howard (1850-1928) en su libro Las ciudades jardin del mañana (1902), donde abogaba por un nuevo planteamiento urbano. Planteaba la necesidad de reformular el espacio urbano industrial, defendiendo su fragmentación y difusión en entidades pequeñas que rompieran con la aglomeración existente, para así facilitar la creación de cinturones ajardinados y agrarios que permitieran mantener la conexión del hombre con el territorio a través de un ambiente óptimo.

Parte de estos principios quedaron refrendados en el paternalismo industrial, ${ }^{9}$ una corriente social que comenzó a implantarse en el XIX consistente en que el empresario proveía a su clase obrera de los servicios sociales que pudiera necesitar (casa, escuela, dispensario médico, economato, instalaciones deportivas, iglesia, etc.), algo que también era empleado como una forma de control sobre sus trabajadores, al hacerlos depender de su trabajo. Unas ideas que Henri De Gorge (1774-1832) había materializado en el Grand-Hornu, en la zona minera de Borinage, dentro la provincia valona de Henao, en Bélgica. Un espacio donde industria y viviendas quedarían unidas por un cuerpo ajardinado en cuyo centro se alzó la figura de su promotor. ${ }^{10}$

\footnotetext{
${ }^{9}$ Los principios de este modelo estarían vigentes durante gran parte del siglo XX, como demuestra el caso de España al ser una vía adoptada durante el franquismo por grupos industriales y el propio Gobierno para impulsar el tenue tejido industrial existente.

10 UNESCO. Grand Hornu. Recuperado de: https://whc.unesco.org/uploads/nominations/ 1344rev.pdf. Fecha de consulta: [16/02/2020].
} 
En todos los modelos indicados, la presencia de zonas de ocio y recreo eran un punto a implementar, si bien era cierto que hacer convivir los mismos con la zona de trabajo no era algo común. Aquí es donde radicaría la novedad de complejo de Peña. En la actualidad es un elemento más, destinado tanto a mejorar el ambiente de trabajo como a generar una imagen asociada a la marca que lo vincule con la naturaleza.

A este aspecto se añadió la consideración por atender los posibles accidentes de trabajo que sus empleados pudieran sufrir, para lo cual contaba con un botiquín. De nuevo una novedad a tener en cuenta, dado que en estas fechas las protecciones laborales no tenían recorrido y los riesgos laborales eran muchos. Con ello, Peña demostraba que no solo había que cuidar de los productos, sino también de los productores, porque de ellos dependían los primeros. El porqué de este interés podría venir refrendado por su propia vida laboral, en la que pasó por diversos puestos que le permitirían ver las dificultades y carencias de las actividades que después gestionaría. Pero también por su propia personalidad, ya que se destacaba siempre su interés por cuidar de su plantilla. Así lo recogía otro artículo ubicado en el mismo diario y día en la sección «Lo del Día»:

«El Sr. Peña aunque no obtiene grandes ganancias en su fábrica de camas de hierro, derrama grandes beneficios entre el numeroso personal de operarios que sostiene, y prueba además, que si tuviera imitadores, en los demás ramos de la industria, no se hubiera perdido aquí tantas como se han perdido.

En esta desconfianza que tiene el capital para arriesgarse en empresas útiles, en las que se necesitan inteligencia, constancia y mucho trabajo, merecen la estimación pública los que dan el ejemplo del Sr. Peña, que no aspira á enriquecerse en poco tiempo, sino á hacer su capital patrimonio, digámoslo así, tan suyo como de sus obreros». ${ }^{11}$

Su fundición se especializaría en un numeroso y variado grupo de elementos: «herrajes para obras, artículos de hidráulica, batería de cocina, herramientas para todos los oficios, armas y utensilios de caza y en general cuanto comprende la producción de la fábrica y todo el extenso ramo de ferretería, todo ello, como queda dicho, en una extensa escala desde lo más modesto a lo más costoso, aunque siempre en las condiciones de calidad excelente (...)».12 Cuenta de ello daban también los numerosos anuncios que en la última década del XIX coparon las páginas de El Diario de Murcia, donde dejaba constan-

\footnotetext{
11 AMM. Hemeroteca. El Diario de Murcia. 11/10/1894, p. 1.

12 AMM. Hemeroteca. El Liberal. 08/09/1905. p. 3.
} 
cia de que realizaba prensas para aceite y vino, y molinos para la aceituna de varias clases y tamaños, ${ }^{13}$ todo tipo de camas negras, doradas o niqueladas, ${ }^{14}$ prensas hidráulicas, escaleras y hacía reparaciones de maquinaria. ${ }^{15}$

De sus talleres también salieron mobiliario urbano, así como elementos empleados en la construcción de puentes y estaciones de ferrocarril de la Región, referenciando de este modo que todo lo que fuera en hierro fundido lo podía realizar, incluidas las columnas que adornarían el Casino de la ciudad de Murcia, donde de nuevo dejó su nombre a modo de firma. Una marca que es común encontrar en los elementos de hierro fundido, donde al realizar productos en serie era normal estampar el nombre del fabricante. También como reclamo publicitario, ya que en un momento en donde todo se quería modernizar, contar con los datos del ejecutor del elemento servía para ubicarlo, un gesto que resulta inusual en una obra como esta. Aunque si bien es cierto que lo que más fama le reportaría, y uno de los productos por los que sería más reconocido, sería por las camas, producto que llevaría a diversas exposiciones universales en las cuales obtuvo varias menciones y diplomas, que transformaría en modernos blasones hechos en hierro que adornarían la oficina de su fábrica.

Su importante labor industrial se vio refrendada con su participación en diversas actividades y organismos destinados siempre a buscar el beneficio de la comunidad. Además de ser uno de los primeros en suscribirse a las parcelas del cementerio (Moreno, 2006: 114), participó en el empréstito iniciado por el ayuntamiento para finalizar sus obras. ${ }^{16}$ Fue miembro de la comisión preparatoria para instalación de la Cámara de Comercio, Industria y Navegación en Murcia, ${ }^{17}$ participando activamente en su puesta en marcha posteriormente. También ejerció como asignado para en la junta municipal, ${ }^{18}$ impulsó las obras del nuevo manicomio de la ciudad con donativos, ${ }^{19}$ formó parte de los jurados de la Audiencia Provincial, ${ }^{20}$ actuó como accionista para

13 AMM. Hemeroteca. El Diario de Murcia. 21/10/1892, p. 4.

14 AMM. Hemeroteca. El Diario de Murcia. 24/02/1887, p. 4.

15 AMM. Hemeroteca. El Diario de Murcia. 20/10/1894, p. 4.

16 AMM. Hemeroteca. El Diario de Murcia. 19/05/1886, p. 3.

17 AMM. Hemeroteca. El Diario de Murcia. 12/11/1886, p. 4.

18 AMM. Hemeroteca. El Diario de Murcia. 24/09/1889, p. 3.

19 AMM. Hemeroteca. El Diario de Murcia. 30/01/1892, p. 3.

20 AMM. Hemeroteca. El Diario de Murcia. 04/01/1894. p. 2. 
promover las corridas de toros, ${ }^{21}$ ejerció como vocal en el Consejo Provincial de Agricultura, Industria y Comercio 22 e hizo donativos para la celebración del Entierro de la Sardina. ${ }^{23}$ Además, su preocupación por el bienestar de los demás le llevó a formar parte del consejo de administración de «La Positiva. Compañía Anónima de Seguros».24

Estas actuaciones, abogadas solo en su nombre, contrastan con la efectuada tras la riada de San Jacinto (11/09/1891), momento en el que tanto él como el personal de la fábrica hicieron una colecta para ayudar a los damnificados. Acción que fue refrendada en una nueva nota de prensa donde se recogieron todos los nombres de los trabajadores que participaron en la misma. De ella se desprende que en ese momento la plantilla estaba formada por 114 obreros, de los cuales solo dos eran mujeres. ${ }^{25}$

Esta extensa relación de puestos y la proyección que sus acciones tuvieron dentro de la vida social de Murcia en el siglo XIX no hicieron otra cosa que aumentar la consideración hacia él y su actividad empresarial. Si bien realmente para él solo había un puesto importante a ocupar: ser el primero entre sus obreros. ${ }^{26}$ Motivo por el cual conservaba y mostraba como un trofeo el banco de herrero donde tantas horas de trabajo pasaría. ${ }^{27}$ Sería precisamente el afecto hacia su trabajo y el orgullo que sentía hacia su profesión lo que haría que escogiera el hierro como material para confeccionar el panteón que debía albergar la morada eterna de su familia. Había sido el material que se lo había dado todo, bueno sería para darle también la vida eterna.

\section{LA TUMBA DE HIERRO DEL CEMENTERIO NUESTRO PADRE JESÚS}

En la primera página de El Diario de Murcia del 29 de marzo de 1899 el mausoleo de Francisco Peña acaparó parte de la primera página con un sugerente título: «La tumba de hierro», que anunciaba la descripción del desarro-

\footnotetext{
21 AMM. Hemeroteca. El Diario de Murcia. 24/01/1899, p. 3.

22 AMM. Hemeroteca. El Diario de Murcia. 19/11/1902, p. 3.

23 AMM. Hemeroteca. El Liberal. 22/02/1906, p. 1.

24 AMM. Hemeroteca. El Diario de Murcia. 08/11/1903, p. 3.

25 AMM. Hemeroteca. El Diario de Murcia. 29/09/1891, p. 2.

26 AMM. Hemeroteca. El Diario de Murcia. 08/09/1905, p. 3.

27 AMM. Hemeroteca. El Diario de Murcia. 11/10/1894, p. 1.
} 


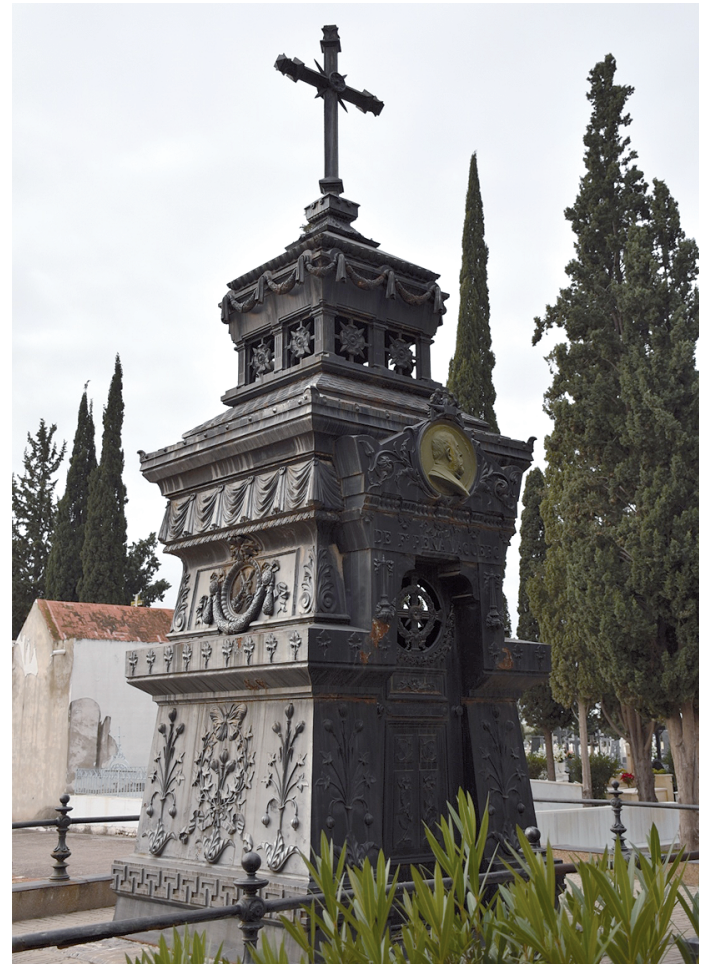

Imagen 2. Visión de conjunto del panteón de Francisco Peña. Autora: Palazón.

llo de la obra y de sus principales aspectos. ${ }^{28}$ Lo primero que se señalaba era que se había hecho en sus propios talleres. Se había iniciado en 1897 y, tras dos años de trabajo, se había ensamblado finalmente. A continuación, se ponía la atención en el material: hierro. Un material tan tenaz y resistente como el propio Peña, que adquirió la forma de un cenotafio cuadrangular, inspirado en un modelo del cementerio parisino de Père Lachaise realizado en mármol (Nicolás, 1992: 24), asentado sobre una base de mármol que se distribuyó en tres alturas decrecientes, las cuales reproducían el mismo modelo decorativo en tres de sus caras, mientras la cuarta albergaba la puerta de acceso con un programa iconográfico diferente. Procedamos a analizarlo. ${ }^{29}$

28 AMM. Hemeroteca. El Diario de Murcia. 29/03/1899, p. 1.

29 La metodología aplicada a este análisis sigue las pautas enmarcadas en Palazón y Molina (2019: 81-82). 


\subsection{Síntesis y materialización de un panteón diferente}

El primer cuerpo partía de una zona de asiento férreo que albergaba en su parte superior una greca que fue definida en el diario como un plinto con meandros. La greca fue un símbolo usado por las culturas mesopotámicas, clásicas y precolombinas con aplicaciones diferentes, pues mientras para algunas aludía a la representación del movimiento de la serpiente, otras volcaban en ella la consideración de un referente acuático en la forma de un meandro (Revilla, 2018: 332). Sería esta última cuestión la que aquí tendría sentido, al subrayar con ello la vinculación que da origen a la vida cristiana a través del bautismo. Pero el agua también participa en la muerte, pues el féretro del difunto también se rocía con agua bendita con la que daría inicio a su nueva vida, la verdadera.

Un agua que serviría de base a una representación de flores de adormidera, un elemento tradicional en el repertorio funerario cristiano que aludía a la vinculación entre el sueño y la muerte. No en vano, en la misa funeral el cura remarca este precepto al indicar que realmente no se está muerto, sino dormido en espera de la resurrección. Cuestión que ya el profeta Daniel había indicado: "Muchos de los que descansan en el polvo de la tierra se despertarán, unos para la vida eterna, otras para vergüenza y horror eternos» (Dn 12, 2). Por último, en la zona central, la planta de adormidera culminaba con una corona de hojas, símbolo de unión entre el principio y el fin, lo mismo que enmarca la muerte para el cristiano, que albergaba una mariposa. Este insecto, resultado de la metamorfosis de un gusano, fue empleado para representar el momento en que el alma abandonaba el cuerpo y volaba fuera de la tumba (Revilla, 2018: 473).

El segundo cuerpo partía de un ático que, como réplica a la greca-meandro, se adornó con hojas de hiedra, que marcaban la verticalidad del conjunto y, con ello, el ascenso al cielo, residencia de la verdadera vida cristiana. Seguidamente, en una nueva sección apiramidada, se ubicó un respiradero flanqueado por una corona de flores «de siempre-vivas; y surmontado por un grupo de cascales», 30 elementos destinados a reforzar que tras la muerte hay vida, en cuyo centro se ubicaron dos antorchas invertidas, que representarían el fin de la luz de la vida terrenal. A ambos lados de este cuerpo, en sus esquinas, dos acroteras con forma de hoja de acanto remataban esta sección. Esta planta había dado origen a la decoración de un estilo griego y se empleó para representar las artes, así como también, debido a que su hoja albergaba pin-

30 lbídem. 
chos, le permitió ampliar su simbología con la consideración de que era idónea para refrendar la superación de adversidades y servir para resaltar un triunfo obtenido con dificultades (Revilla, 2018: 16). Sobre él descansaba un plinto adornado con una colgadura de tela, de la misma entidad que adornaba los catafalcos para custodiar el cuerpo de Cristo durante los días finales de la Semana Santa, que quedaría cobijado por una cornisa y un tejado a dos aguas que incluía acroteriones en sus esquinas.

El último cuerpo, el tercero, reduciría nuevamente las dimensiones del segundo, y se formaría por cuatro frentes distribuidos a través de tres fragmentos de pilastras que albergaban a su vez dos respiraderos en cada uno de sus bloques, que adquirieron la forma de una flor abierta. Sobre esta sección iría la "urna cineraria» 31 adornada, de nuevo, con guirnaldas de siemprevivas y colgantes de paños, encima de su tapa se alzaría una cruz de 1,90 metros, que, sumada al resto del conjunto, daría una altura de 6,99 metros.

La zona de acceso, donde se ubicó la puerta de entrada, presentaba algunas diferencias en los elementos decorativos con respecto al resto del conjunto. De nuevo se encontraba la greca-meandro, que recorría todo el conjunto salvo en la zona concreta de la puerta, que quedó retranqueada y no empleó esta decoración en su parte baja. No debería extrañar esta cuestión, dado que el agua vería interrumpido su discurrir para permitir al hombre descender a su morada de descanso, separando así el agua de la tierra. Su forma de talud fue aprovechada para ubicar en su parte inferior de nuevo dos plantas de adormidera, que serían seguidas de dos antorchas invertidas, que inauguraban su segundo cuerpo, precedidas del zócalo de hojas de hiedra que rodeaba el conjunto. Sobre ellas se alzaba el nombre de la familia a la que estaba destinada tan magna obra: «Familia de Fo Peña Vaquero». A continuación, presidía la zona de acceso un retrato de perfil del propio Peña, hecho en un alto relieve, «decorado con una elegante guarnición de correcta, ataviada taila y como término superior de esta, se alza un trofeo de útiles y herramientas de herrería y maquinaria».32 Fue aquí donde se ubicaron el martillo y el yunque, elementos esenciales de su trabajo, junto con lo que, debido a su forma de rueda dentada, podría aludir a una de las ruedas que se empleaban para dotar de energía a las máquinas.

La puerta no fue ajena a la decoración. En ella se incluyeron dos tallos de adormidera florecida con su hoja característica, no empleando la de la hiedra,

31 Ibídem.

32 Ibídem. 


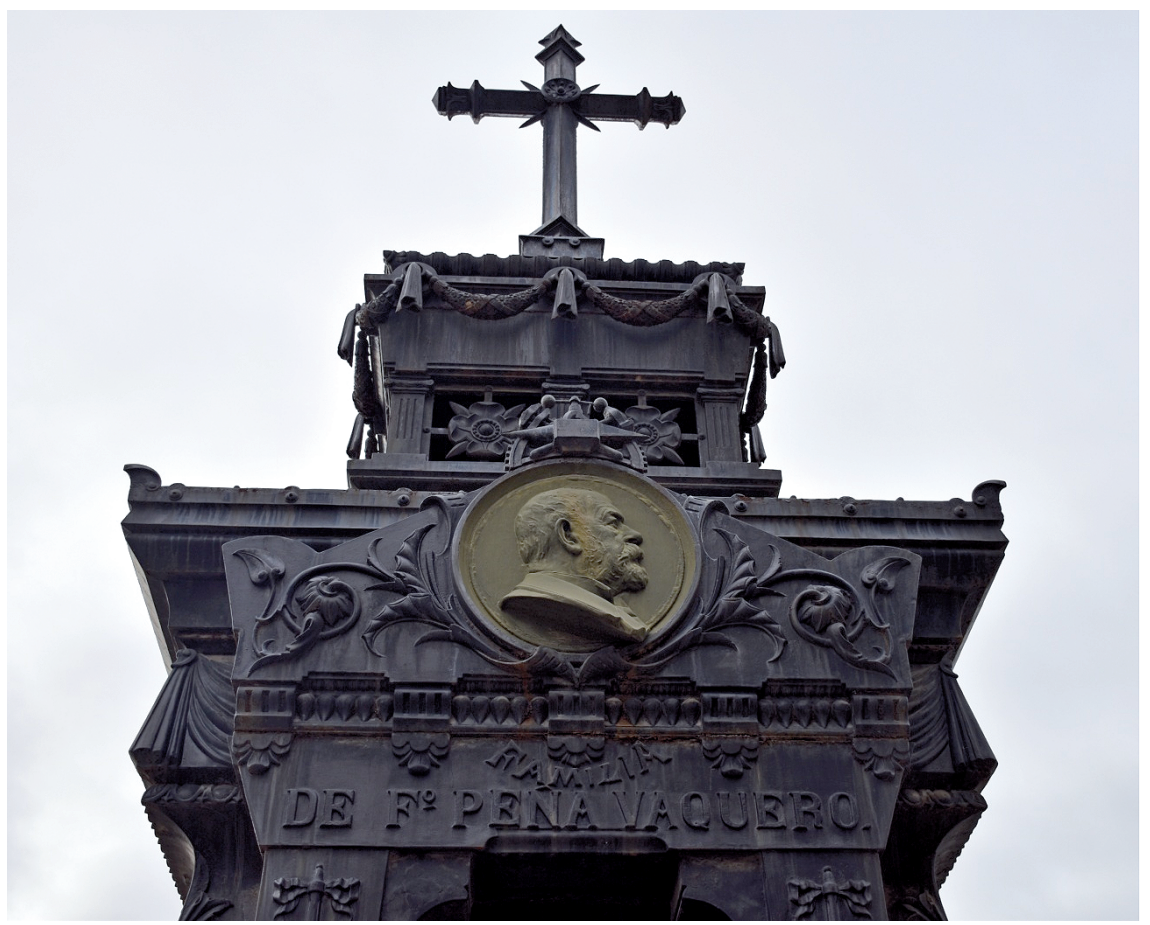

Imagen 3. Detalle zona de acceso panteón. Autora: Palazón.

la cual aparece en la parte superior dentro de dos filigranas de gran calidad. Resultaba llamativo que la flor, paso necesario para su declive final, estuviera justo en la puerta, como queriendo remarcar que, una vez traspasada, solo esperaba la decadencia de la forma corporal bajo la que uno había vivido. Sobre ellas estaba grabada la alusión explicita que recogía la información sobre la ejecución de tan llamativa obra: «Construido en los talleres de D. Francisco Peña. Murcia 1899", repitiendo así dos veces el nombre del promotor y propietario. Un nuevo respiradero calaba la puerta con una cruz rodeada de flores, que la nota de prensa considera adormideras. ${ }^{33}$

La ejecución de la obra se hizo en hierro fundido, misma técnica que se emplearía para la realización de la balaustrada que enmarcaría las dimensiones reales del panteón, pues Peña fue uno de los primeros suscriptores de parcelas del cementerio, obteniendo dos parcelas en 1883 que amplió con una más en 1896 (Moreno, 2006: 114).

33 lbídem. 
Sobre este singular ejercicio no solo se proyectó el nombre de Peña. La idea, pese a partir de un modelo parisino, fue ajustado por el artista Mariano Garrigós, escultor murciano del XIX, a las pretensiones de Peña. Mientras que su busto estuvo a cargo de Juan Dorado Brisa, un escultor valenciano que le permitía vincular su morada eterna con su origen. Pero hubiera sido imposible, al parecer, sin la pericia y entrega del maestro de la fundición: Wenceslao Carceller Peña, sobrino de Peña y continuador de su legado, quien se construiría un panteón propio, de menor entidad, pero también en hierro fundido, en las proximidades de su tío. Conviene tener en cuenta que hubo que hacer por separado cada cuerpo y luego ensamblarlos en una estructura final que pesaba 9.700 kilos. Para proteger su corrosión de las inclemencias ambientales, se cubrió de varias capas de una composición de plombagina.

Una vez finalizado, Peña quiso mostrarlo, y para ello no dudo en exponerlo al público en el jardín de su fábrica, llegando incluso a informar de que se podría visitar «diariamente desde la diez de la mañana á las seis de la tarde, previo permiso del propietario Jefe de la fábrica». 34

\subsection{Trabajo y muerte en un programa iconográfico personalista}

El panteón realizado resultaba ser un ejercicio más para refrendar la posición de Peña en una sociedad más burguesa que industrial, donde el trabajo, y más todo aquel que no tuviera un desarrollo intelectual únicamente, seguía viéndose como un elemento negativo socialmente. Ello justificaría la elección del material, un material que como la propia muerte se trabaja, moldea y transforma hasta adquirir una nueva forma, que frente a la desintegración de la vida dejara un referente duradero que pretendía ser eterno. Así como la inclusión de los útiles de su trabajo, los cuales servirían para dejar constancia de que por ellos alcanzó sus metas y su nombre perduraría en el tiempo.

Esas herramientas, parte de su banco de trabajo, habían estado acompañándolo en su vida, por eso tenían que estar también en su panteón, y, dentro del mismo, justo sobre su efigie. Algo también novedoso en estos momentos, en donde las imágenes de los fallecidos todavía no se han comenzado a introducir en las lápidas, y mucho menos se incluían sobre las fachadas de los panteones. Un rostro dispuesto de perfil combinando varios grados de grabado que hicieron sobresalir el cuello de su chaqueta, camisa y corbata, que adoptaba los modelos numismáticos y traslada al modelo de retrato que impe-

34 Ibídem. 
ró durante buena parte del Renacimiento italiano, cuando los mecenas de las artes dejaron su rostro impreso en pinturas que recuperaban los modelos de las monedas romanas.

Peña, quizás sin pretenderlo, parece querer recuperar la figura del dios griego Hefesto -Vulcano en la vertiente latina-, el dios del fuego, los metales y la metalurgia, el único que trabajaba con sus manos y quien, como él, lo hacía en una fragua, ayudado por cíclopes, haciendo las armas de los héroes griegos (Grimal, 2010: 228-229), como ejemplificó en su pintura Velázquez. Aquí no se proyectó el espacio de trabajo, la fábrica en sí misma, pero sí que se incluyó dónde se había hecho. Las puertas del panteón resultaban ser una antítesis de las puertas de la fábrica: unas referenciaban la entrada al mundo de la muerte, las otras la entrada al mundo del trabajo. Unas puertas que era necesario traspasar: las primeras para alcanzar la vida eterna, las segundas para poder subsistir con las mejoras que la industrialización ofrecía a una ciudad con poca proyección empresarial. En relación con ello, conviene tener en cuenta que, en la fachada de su fábrica, los seis blasones distintivos de los premios y menciones alcanzados no solo debían verse como emblemas de su éxito, sino como sustitutos del blasón nobiliario o escudo familiar que él no podía lucir, pero que no era tan importantes cuando el éxito te encumbraba por otros méritos que podías ostentar.

Frente a este programa iconográfico, enmarcado en la zona de acceso, el resto de la decoración desarrollada en sus tres restantes caras y cuerpos, atendía a los preceptos tradicionales de la iconografía funeraria. A través de la configuración de las plantas, mariposas, flores y antorchas invertidas, se creó un discurso interpretativo al servicio de la esperanza de la resurrección. Ello queda resaltado en la posición en vertical de las plantas de adormideras, las mariposas, así como con el zócalo de hojas de hiedra, que iban marcando la dirección hasta llegar a una cruz vacía, alusión a la resurrección que espera a todo buen cristiano.

Resulta también significativo que se aludiera en la nota de prensa a que, en la parte alta, bajo la cruz, lo que hay representado fuera una urna cineraria. En estos momentos la inhumación era la forma de enterramiento, pero ese aporte, donde de nuevo el fuego tendría una parte activa, nos hace pensar en la idea de proyectar sobre el panteón la consideración de que, aunque los enterramientos se produjeran en su parte baja, los restos de los allí custodiados ascenderían hacia ese espacio en su discurrir a la vida eterna. También no se debe perder de vista que la ceniza marca el inicio de la cuaresma, cuando el sacerdote la imprime en la frente diciendo: «Polvo eres y en polvo te convertirás», representando la fugacidad de la vida y la necesidad de no pecar y practicar el ayuno y la penitencia para alcanzar la resurrección. 
Por último, ponemos la atención en la inclusión de los cuatros elementos de la naturaleza. Si bien a simple vista se podrían distinguir el agua, en el meandro con forma de greca, y el fuego, en las antorchas que aludirían al fin de la luz de la vida con su posición inversa. La tierra quedaría incorporada con el espacio subterráneo destinado a albergar los cuerpos de los fallecidos, una tierra en la que reposaran hasta que inicien su ascenso al más allá. Y el aire no solo estaría presente por su propio estado rodeando todo el conjunto, sino que, por la apertura de respiraderos, esenciales en una estructura de este tipo donde las condiciones climáticas del lugar harán que el interior del panteón alcance temperaturas altas, permitirían renovar el aire interior del panteón de forma continua y constante.

\section{DISCUSIÓN DE RESULTADOS Y CONCLUSIONES}

La muerte iguala a los hombres y los aleja de todas sus pertenencias materiales. Esa máxima, sin embargo, lleva implícita una segregación, ya que el enterramiento que cada uno adopte reflejará su forma de vida, de tal modo que la clase social estará también explícitamente representada en el cementerio (Nicolás, 1994).

En el caso estudiado, esto va más allá, ya que Peña refrendó en su panteón no solo su puesto en la sociedad como industrial, sino también su amor por el trabajo. Tengamos en cuenta que desde el Génesis el trabajo estaba asociado al pecado original: «Por haber escuchado la voz de tu mujer y comido del árbol del que yo te había prohibido comer, maldito sea el suelo de tu causa: sacarás de él tu alimento con fatiga todos los días de tu vida. Te producirá espinas y abrojos, y comerás la hierba del campo. Comerás el pan con el sudor de tu rostro, hasta que vuelvas al suelo, pues de él fuiste tomado. Porque eres polvo y al polvo tornarás» (Gn 3, 17-19). Con la muerte de Cristo la humanidad redimió el pecado de los primeros padres, pero no se libró del trabajo. Es por ello que el industrial concebiría su panteón como un moderno monumento alejado de los preceptos tradicionales, en donde la muerte y la resurrección conjugaban elementos en un repertorio iconográfico que buscaba insistir en el hecho teologal de que la muerte es algo necesario para alcanzar la salvación.

El hierro fundido fue un material muy empleado en la arquitectura funeraria, sobre todo para abordar sus elementos decorativos, caso de cruces, puertas o vallas, objetos que se llegaban a hacer en serie, como imponía el nuevo modelo productivo, y que formaban parte de los catálogos que las fundiciones fueron difundiendo de un país a otro, facilitando así la distribución de modelos y formas (Silva, 2005). Pero estas no serían sus únicas aplicaciones. En 
Estados Unidos fue empleado para hacer diferentes estructuras empleadas para albergar, proteger y reconocer al difundo. De hecho, en 1848, Almond Fisk patentó un modelo de ataúd realizado en este material que quería sustituir el endeble y fácil de abrir ataúd de madera, se buscaba así evitar los robos que se producían en las tumbas. Una idea que también facilitaba un sellado hermético que era beneficioso para evitar la transmisión de enfermedades, y resultaba óptimo para trasladar cuerpos entre distancias considerables. Pero sus usos no se quedarían aquí, pues también se emplearía para hacer tumbas, como ejemplifica el cementerio de Fairburn City, en el estado de Georgia, donde se custodian algunas de las realizadas por Joseph R. Abrams, quien proyectó una sepultura bajo tierra que en la parte superior se protegía con una forma de hierro similar a una concha con la que se quería guardar la estructura interna y servir de homenaje al fallecido (Rylands, 2015). En otros casos se adoptó este material para hacer lápidas al pensar que era muy resistente, pero el paso del tiempo demostraría que se oxidaban y podían llegar a quebrarse. Por último está su empleo para realizar mausoleos, como el ejemplo aquí analizado, dado que ofrecía la posibilidad de hacer piezas prefabricadas que ensambladas permitían obtener una estructura sobre la cual se podían personalizar algunos elementos decorativos. Así lo testimonian los ejemplos de los mausoleos de Pomeroy y Slatter (Kazek, 2019), en el cementerio de Magnolia de Alabama, y el de Karstendiek Tomb en el cementerio de Lafayette, de Nueva Orleans.

De esta forma, el hierro fundido demostró que no solo era apto para proyectar de nuevos medios de trabajo y productos, sino también para dar forma a nuevas necesidades, incluidas las artísticas, demostrando que el arte contemporáneo no se abstraía de los materiales de su época. Tengamos en cuenta que en París con motivo de la exposición universal de 1889 se elevó la Torre Eiffel, una obra que lograría convertirse en la referencia del evento y en el símbolo de Francia. Si recordamos que los productos de Peña participaban de estas exposiciones, y que conocía los principales referentes industriales y culturales europeos, no nos debe extrañar que para distinguirse en el cementerio optara por este material que también conocía, no siguiendo la vía general de emplear mármol o hacer uso de un modelo en mampostería.

La suma de todo ello hizo que su ideario de vida, junto con los preceptos cristianos de la muerte, quedaran enmarcados en un panteón que, más que un alegato a la muerte y la resurrección, incidía en la necesidad de progresar para hacer avanzar la sociedad hacia nuevos logros, que permitieran conseguir beneficios que repercutieran en todos los ámbitos. 


\section{BIBLIOGRAFÍA}

Archivo Municipal de Murcia. Disponible en: https://www.archivodemurcia.es/Inicio.

Giedion, S. (1978). La mecanización toma el mando. Barcelona: Gustavo Gili. Grimal, P. (2016). Diccionario de mitología griega y romana. Barcelona: Paidós. Grinán Montealegre, M., López Sánchez, M. \& Palazón Botella, M. D. (2008). Francisco Peña Vaquero y la fundición de hierro en Murcia. En Álvarez Areces, M. Á. (coord.), Del hierro al acero. Forjando la historia del patrimonio industrial metalúrgico. Gijón: CICEES, 261-273.

Hemeroteca Digital Biblioteca Nacional de España. Disponible en: http:// www.bne.es/es/Catalogos/HemerotecaDigital/.

Kazek, K. (2019). The intricate beauty of cast-iron in Alabama's Victorian grave covers, caskets, fences, mausoleums. Al.com. Disponible en: https: //www.al.com/living/2015/11/the_intricate_beauty_of_cast-i.html. [15/03/2021].

Mañas Borrás, L. (2013). La artesanía industrial en Valencia. La Fundición Primitiva Valenciana (1850-1890). Disponible en: http://www.racv.es/ institucional/files/La_artesania_industrial_en_Valencia.pdf (sin datos publicación) [19/05/2020].

Moreno Atance, A. M. (2006). Cementerios murcianos: Arte y arquitectura. Tesis doctorales Universidad Complutense. Disponible en: https:// eprints.ucm.es/7150/ [20/02/2020].

Nicolás Gómez, S. (1992). El estilo neogótico a finales del siglo XIX en la arquitectura funeraria del cementerio de Ntro. Padre Jesús en Murcia y en otros cementerios del municipio. Murgetana, 85, 21-32.

Nicolás Gómez, S. (1994). La morada de los vivos y la morada de los muertos: Arquitectura doméstica y funeraria del siglo XIX en Murcia. Murcia: Editum.

Palazón Botella, M. D. y Molina Gómez, J. A. (2019). Estudio iconográfico del panteón de las familias Erades-Navarro en el Cementerio de Nuestro Padre Jesús de Murcia. Revista Murciana de Antropología, 26, 77-94. Disponible en: https://revistas.um.es/rmu/article/view/368581 [20/02/ 2020].

Revilla, F. (2018). Diccionario de iconografía y simbología. Madrid: Cátedra. Rylands, T. (2015). Joseph R. Abrams: Inventor of the Cast Iron Grave Cover. Blog Adventures in Cemetery Hopping. A blog by Traci Rylands. Disponible en: https://adventuresincemeteryhopping.com/2015/01/23/joseph-rabrams-inventor-of-the-cast-iron-grave-cover/ [15/03/2021]. 
Silva Contreras, M. (2005). Hierro fundido en plazas y cementerios del siglo XIX: Caracas y Valencia entre incontables ciudades. Apuntes, 18 (1-29), 90-105.

UNESCO. Grand Hornu. Disponible en: https://whc.unesco.org/uploads/ nominations/1344rev.pdf. [16/02/2020]. 
